\title{
Parametric analysis of AAR influent factors on thin-walled columns
}

\section{Análise paramétrica dos fatores influentes da RAA em pilares parede}

E. L. MADUREIRA edmadurei@yahoo.com.br

E. C. RODRIGUES a

edmilsoncrodrigues@gmail.com

\begin{abstract}
The chemical reaction involving the alkalis of the cement and some minerals of the concrete aggregates, the Alkali-Aggregate Reaction or, simply, the AAR, promotes swelling and material damages. Despite the development stage of the researches on this pathology effects, its solution modeling still lacks refinement. The numerical simulation is an important resource for the structural damages evaluation due to AAR, and their repairs. The aim of this work is the numerical simulation of concrete thin-walled columns, affected by the AAR, from the finite element approximation on an orthotropic nonlinear framework, and a thermodynamic model designed to the assessment of the AAR swelling, with highlight on the compressive stress, the reinforcement and the temperature influences on the phenomenon. The obtained results revealed that the AAR induced the concrete strength decrease and the consequent reduction in preventive safety margin to the material failure, being more precocious at higher temperatures.
\end{abstract}

Keywords: simulation, alkali-aggregate reaction, column, temperature.

\section{Resumo}

A reação química que envolve os álcalis do cimento e alguns minerais dos agregados de concreto, a reação álcali-agregado ou, simplesmente, a RAA, promove danos materiais e expansão. Apesar do avanço das pesquisas sobre os efeitos desta patologia, a modelagem de sua solução ainda carece de refinamento. A simulação numérica é um recurso importante para a avaliação de danos estruturais devido a RAA e os seus reparos. O objetivo deste trabalho é a simulação numérica de pilares parede de concreto, afetados pela RAA, A partir da aproximação por elementos finitos sobre um esquema de cálculo ortotrópic não-linear e um modelo termodinâmico, voltado para a avaliação das expansões por RAA, destacando a influência da tensão de compressão, da armadura e da sobre o fenômeno. Os resultados obtidos revelaram que a RAA induziu a diminuição da resistência do concreto e a consequente redução da margem de segurança prévia à ruína do material, sendo mais precoce para temperaturas mais elevadas.

Palavras-chave: simulação, reação álcali-agregado, pilar, temperatura. 


\section{Introduction}

The Alkali-Aggregate Reaction, or simply the AAR, is a chemical transformation involving the alkalis from Portland cement and some minerals from concrete aggregates [16], and aroused interest in the Civil Engineering scope when it was observed some damages in concrete structures affected by its deleterious action. The pathology includes cracking that can culminate in widespread ruin and impairment of serviceability.

Despite the availability of experimental results, the formulation of the problem still lacks refinement, so that the effectiveness of your solution remains doubtful. The numerical simulation represents a suitable tool for the quantification of the damages caused by the AAR, may assist the structural recovery tasks and serve as a basis for design criteria formulation.

The most of the models so far developed adopts linear constitutive relations, despite the nonlinear concrete behavior, and the AAR random and its anisotropic nature.

The aim of this work is the numerical simulation of the mechanical performance of reinforced concrete thin-walled columns, affected by the swelling due to the AAR, emphasizing the compressive stress magnitude, the steel reinforcement ratio and the temperature level influences on the phenomenon.

In order to achieve such purpose it was used a computational support that was developed on the basis of the finite element method on an orthotropic framework and nonlinear constitutive relationships for concrete, in addition to a thermodynamic model for the assessment of the deformations due to AAR.

\section{Modeling}

\subsection{Concrete response to loading}

The numerical analysis was performed on an incremental iterative procedure and finite element approach adopting the orthotropic nonlinear formulation proposed by KWAK and FILIPPOU [9], from which the constitutive matrix is defined through the equivalent strains " $\varepsilon_{\mathrm{ei}}$ ", that are given by:

$$
\varepsilon_{e i}=\varepsilon_{i}+D_{i j} \varepsilon_{j} / D_{i i}
$$

The "i" and "j" indexes refer to principal plane direction. The " $D_{i j}$ " parameters represent the constitutive matrix elements.

For the simulation of concrete in compression it was adopted the constitutive relationships proposed by HOGNESTAD [7] whose hardening branch, OA segment of the curve illustrated in figure 1 , is represented by the form:

$$
\sigma_{i}=\frac{2 . \sigma_{i p}}{\varepsilon_{i p}}\left(1-\frac{\varepsilon_{e i}}{2 . \varepsilon_{i p}}\right) . \varepsilon_{e i} \text { for } \varepsilon_{\mathrm{ip}}<\varepsilon_{\mathrm{ei}}<0
$$

The parameters " $\sigma_{\mathrm{ip}}$ " and " $\varepsilon_{\mathrm{ip}}$ " represent the concrete peak stress and its correspondent strain beyond every "i" principal direction.
Figure 1 - Stress strain curve of concrete

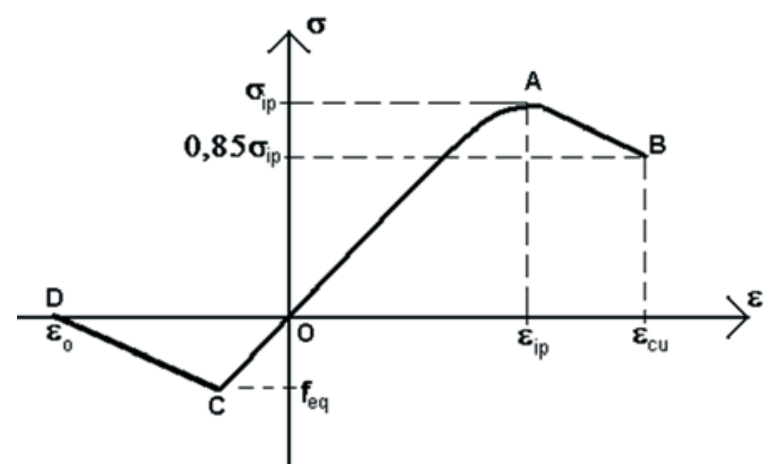

The adopted concrete deformation module is the secant modulus " $\mathrm{E}_{\mathrm{c}}$ " that is obtained according to [1].

The concrete ultimate stresses are defined from the failure envelope proposed by KUPFER and GERSTLE [8], figure 2, whose analytical representation in biaxial compression state is:

$$
\left(\beta_{1}+\beta_{2}\right)^{2}-\beta_{2}-3.65 \beta_{1}=0
$$

where, $\beta_{1}=\sigma_{1} / f_{c}$ and $\beta_{2}=\sigma_{2} / f_{c}$, and $\sigma_{1}$ and $\sigma_{2}, \sigma_{2}<\sigma_{1}<0$, are the principal stresses. " $f_{c}$ " is the concrete uniaxial compressive strength. If $\alpha=\sigma_{1} / \sigma_{2}$ in equation 3, the concrete peak stresses,

\section{Figure 2 - Failure envelope to the biaxial state of stresses of concrete}

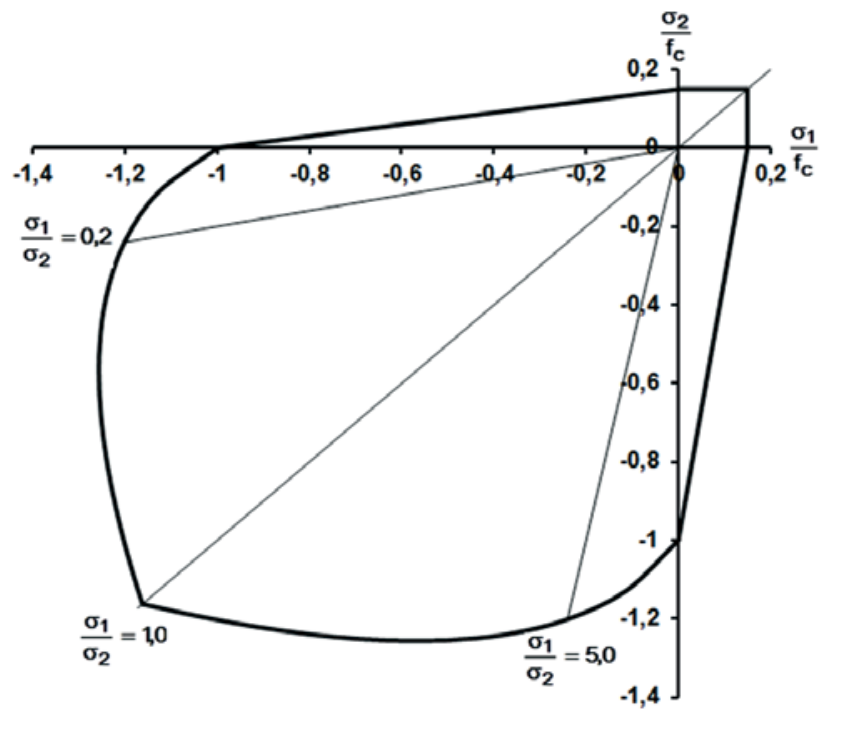


on the principal directions, would be given by:

$$
\sigma_{2 c}=\frac{1+3.65 . \alpha}{(1+\alpha)^{2}} f_{c} \text { and } \sigma_{1 c}=\sigma_{c u}=\alpha . \sigma_{2 c}
$$

The strains related to peak stresses in biaxial compression state, " $\varepsilon_{2 p}$ " and " $\varepsilon_{1 \mathrm{p}}$ ", according to [9], would be obtained from the expressions:

$$
\begin{aligned}
& \varepsilon_{2 p}=\varepsilon_{c o}\left(3 \beta_{2}-2\right) \text { and } \\
& \varepsilon_{1 p}=\varepsilon_{c o}\left(-1.6 \beta_{1}^{3}+2.25 \beta_{1}^{2}+0.35 \beta_{1}\right)
\end{aligned}
$$

where $\beta_{1}=\frac{\sigma_{1 p}}{f_{c}}$ and $\beta_{2}=\frac{\sigma_{2 p}}{f_{c}}$. The parameter " $\mathrm{c}_{\mathrm{co}}$ " is the strain corresponding to the compressive peak stress in uniaxial state of stress.

For concrete subjected to biaxial state of stresses, it was adopted the constitutive relationship on incremental form proposed by DESAI and SIRIWARDANCE [5], according the equation:

$$
\left|\begin{array}{l}
d \sigma_{1} \\
d \sigma_{2} \\
d \tau_{12}
\end{array}\right|=\frac{1}{1-v^{2}}\left|\begin{array}{ccc}
\mathrm{E}_{1} & v \sqrt{E_{1} E_{2}} & 0 \\
v \sqrt{\mathrm{E}_{1} \cdot E_{2}} & \mathrm{E}_{2} & 0 \\
0 & 0 & \left(1-v^{2}\right) . \mathrm{G}
\end{array}\right| \cdot\left|\begin{array}{l}
d \varepsilon_{1} \\
d \varepsilon_{2} \\
d \gamma_{12}
\end{array}\right|
$$

The " $d \sigma_{1}$ ", " $d \sigma_{2}$ " e " $\mathrm{dr}_{12}$ " parameters presented on equation 6 are the stress increments on the principal directions. The "E, 's" parameters are the tangent deformation modules relating to such directions and " $v$ " is the Poisson's ratio. The " $G$ " parameter is the transversal deformation module that is given by:

$$
\left(1-v^{2}\right) \cdot G=0.25\left(E_{1}+E_{2}-2 v \sqrt{E_{1} \cdot E_{2}}\right)
$$

In this analysis were adopted the quadratic approximation isoparametric finite elements.

The solid mass of concrete region is represented by the plane eight-node quadrilateral elements Q8, as shown in figure 3.a.

\subsection{Steel response to loading}

The steel behaviour is considered as been elastic perfectly plastic and the reinforcement steel bars are simulated by bar three-node elements L3, figure 3.b. In this way, the stiffness matrix " $\mathrm{K}$ " is expressed by:

$$
K=\frac{2 A E}{L}\left[\begin{array}{rrr}
1 & 0 & -1 \\
0 & 1 & -1 \\
-1 & -1 & 2
\end{array}\right]
$$

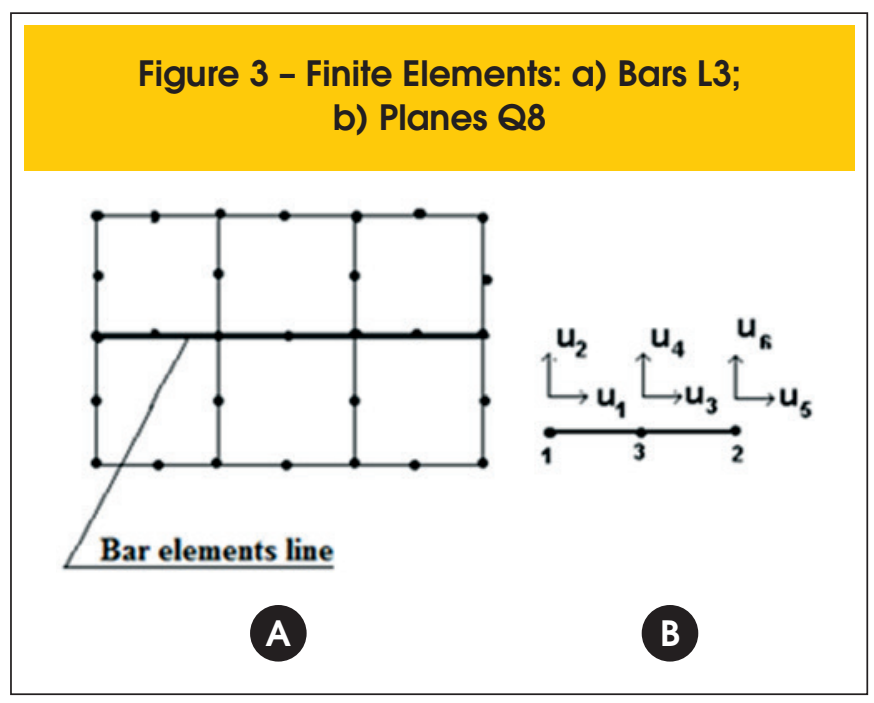

The parameter " $E$ " is the steel Young's modulus, " $A$ " is the reinforcement bar elements cross sectional area and " $\mathrm{L}$ " is the bar finite element length.

\subsection{Alkali-aggregate reation swelling effect}

For the swelling over time simulation it was adopted the thermodynamic formulation proposed by CAPRA and SELLIER [3] that correlates the deformations by AAR to the kinetic of the reaction in the form:

$$
\begin{aligned}
& \varepsilon^{R A A} \approx 0 \text { for } A<A_{O} \\
& \varepsilon^{R A A}=\frac{\varepsilon_{O}}{A_{O}}\left(A-A_{O}\right) \text { for } A>A_{0}
\end{aligned}
$$

where the " $A$ " parameter is the reacted alkalis content over time; " $A$ " is the " $A$ " value corresponding to the beginning of the concrete matrix swelling by $A A R$, and, " $\varepsilon_{0}$ " is the deformation parcel to be subtracted from the total value, with the aim to consider the time gap between the beginning of the reaction and the instant in which the concrete matrix expansion is triggered, as shown in Figure 4. For the reaction kinetic modeling, CAPRA and BOURNAZEL [2], has proposed the equation:

$$
\frac{d A}{d t}=k(T)(1-A)
$$

for which " $k(T)$ " is the kinetic constant associated to the Arhenius law, that is evaluated from:

$$
k(T)=k_{o} e^{\frac{-E_{a}}{R T}}
$$




\section{Figure 4 - Schematic chart for definition of the parameters " $\varepsilon_{0}$ " and " $A_{0}$ "}

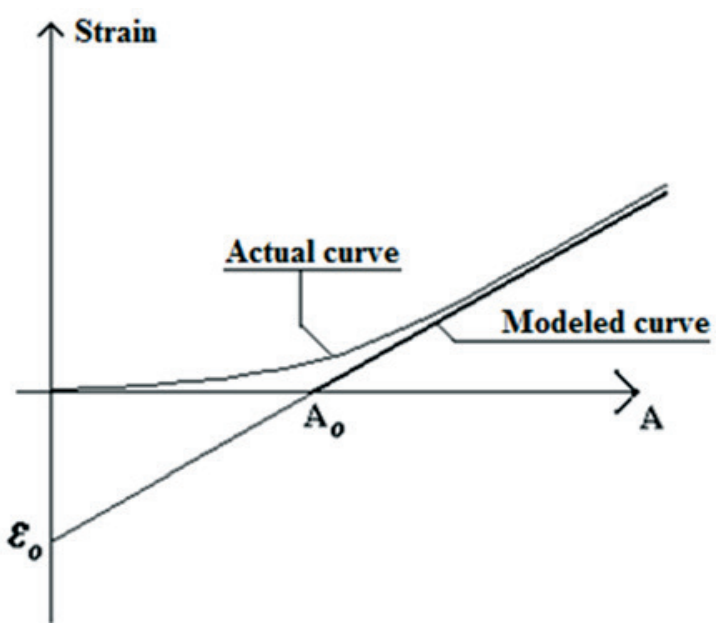

where " $E_{a}$ " is the reaction activation energy, "R" is the ideal gas constant, "T" is the temperature and " $\mathrm{k}_{\mathrm{o}}$ " is the basic kinetic constant. The solution for equation 10 is:

$$
A=1-\left(1-A_{o}\right) e^{-k t}
$$

Resulting for Equation 9, in the range at $\mathrm{A}>\mathrm{A}_{\mathrm{o}}$, the relationship:

$$
\varepsilon^{R A A}(t, T)=\frac{\varepsilon_{o}}{A_{o}}\left(1-A_{o}\right)\left(1-e^{-\left(k_{o} e^{-E_{a / R T}}\right) t}\right)
$$

The confining stress influence was considered from the criterion proposed by CHARLWOOD [4], expressed in the form:

$$
\begin{aligned}
& \mathbf{0} \leq \sigma_{\boldsymbol{i}} \leq \sigma_{\boldsymbol{L}} \rightarrow \varepsilon_{\boldsymbol{g}}=\varepsilon_{\boldsymbol{u}} \\
& \sigma_{L} \leq \sigma_{i} \leq \sigma_{\max } \rightarrow \varepsilon_{g}=\varepsilon_{\boldsymbol{u}}-K \cdot \log _{10}\left(\sigma_{i} / \sigma_{L}\right)
\end{aligned}
$$

where " $\sigma_{i}$ " is the principal stress in the "i" direction, expressed in $\mathrm{MPa}$, " $\varepsilon_{\mathrm{g}}$ " is the confined deformation, " $\varepsilon_{\mathrm{u}}$ " is the unconfined deformation. " $\sigma_{L}$ ", whose value may be fixed approximately equal to $0.3 \mathrm{MPa}$, is the stress below which the expansion may be considered as unconfined one. The parameter " $\sigma_{\max }$ ", whose magnitude is closed to $8.0 \mathrm{MPa}$, is the stress at which the AAR deformation may be considered null, and the "K" constant is the slope of the straight line $\varepsilon \times \log \sigma$.

The moisture content influence on the phenomenon is expressed through the curve proposed by POOLE [14], expressed on the form of the equation 15 .

$$
F(H)=H^{m}
$$

where " $\mathrm{m}$ " is an adjustment parameter that must be considered as equal to 8 . " $\mathrm{H}$ " is the moisture content value.

To express the degradation of concrete by AAR, was adopted a framework similar to that proposed by PIETRUSZCZAC [12], that was adapted by RODRIGUES [15] to the deformation by AAR progress according CAPRA and SELLIER [3], that resulted on the relationships:

$$
\begin{aligned}
& E=E_{o}\left[1-\left(1-A_{E}\right)\left(1-\frac{1}{1-A_{o}} e^{-\left(k_{o} e^{-E_{a} / R T}\right) t}\right)\right] \text { (16) } \\
& f_{c}=f_{c o}\left[1-\left(1-A_{f}\right)\left(1-\frac{1}{1-A_{o}} e^{-\left(k_{o} e^{-E_{a} / R T}\right) t}\right)\right]
\end{aligned}
$$

for which " $E$ " and " $E_{0}$ " are the final and initial deformation modules, respectively, and, similarly, " $f_{c}$ " and " $f_{c o}$ " refer to the compressive strength. The parameters " $A_{E}$ " and " $A_{f}$ " represent the concrete deformation modulus and compressive strength degradation intensity factors, respectively.

The concrete failure possibility analysis was performed taking into reference the Normalized Stress that was defined as the ratio between the stress magnitude on the concrete solid mass and its strength values at the considered instant of time. So that, the Normalized Stress represents a dimensionless parameter whose value is little than the unit and reach such limit values in those cases in which the failure is imminent.

\section{Table 1 - Program validation: displacements by AAR}

\begin{tabular}{|cccc|}
\hline \multicolumn{4}{|c|}{ Displacements $\left(\mathbf{1 0}^{-3} \mathbf{~ m m}\right)$} \\
Time ( Days ) & $\begin{array}{c}\text { Theoretical } \\
\text { model }\end{array}$ & $\begin{array}{c}\text { Numerical } \\
\text { model }\end{array}$ & $\begin{array}{c}\text { Difference } \\
(\%)\end{array}$ \\
\hline 75 & 5.27 & 5.24 & 0.6 \\
\hline 150 & 9.90 & 9.80 & 1.0 \\
\hline 300 & 17.40 & 17.30 & 0.6 \\
\hline 600 & 28.30 & 28.10 & 0.7 \\
\hline 1200 & 41.20 & 40.90 & 0.7 \\
\hline 2500 & 54.00 & 53.60 & 0.7 \\
\hline 5000 & 62.90 & 62.50 & 0.6 \\
\hline 10000 & 68.60 & 68.10 & 0.7 \\
\hline
\end{tabular}


Figure 5 - Problem domain and finite element mesh

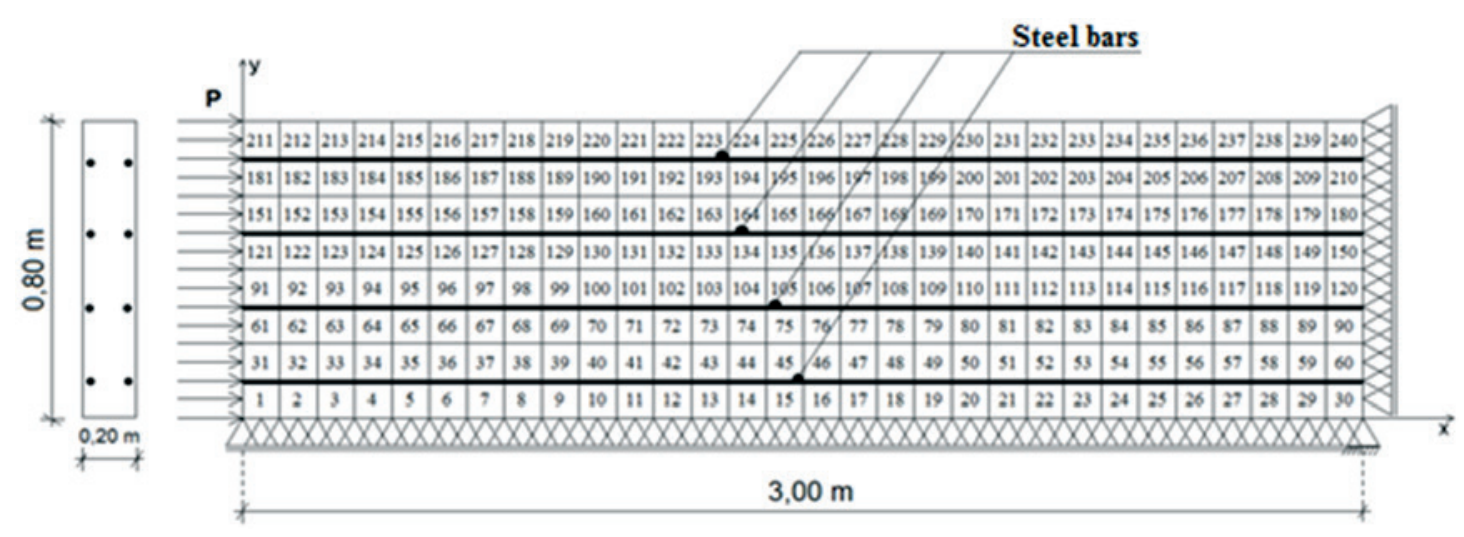

\section{Computational support}

In this work it was applied the software non-Linear Constitutive Analysis-ACNL, based on the finite element method (FEM) and written in the FORTRAN codification as described in [10]. The computational code includes in its algorithmic framework the formulations of the bar and the plane elements, both isoparametrics, on a quadratic approximation. The displacement fields were plotted from the graphic post-processor named NLPOS developed by PITANGUEIRA and PARENTE Jr [13], while the stress fields were drawn up from the graphic postprocessor PROJECT1 developed by MADUREIRA and SILVA [11].

\section{Computational program validation}

For its validation purpose, the program was used to analyze, in a plane state of stresses, a concrete thin-walled column, $3.00 \mathrm{~m}$ length and rectangular cross-section $0.20 \mathrm{~m}$ width and $1.00 \mathrm{~m}$ height, reinforced by eight $10 \mathrm{~mm}$ diameter bars. The structural member is subjected to an axial load of $800 \mathrm{kN}$. The results of such analysis were compared with their corresponding values, obtained by calculations that were carried out from a simplified model, drawn up on the basis of the Solid Mechanic Postulates, in the uniaxial state of stresses, as performed by RODRIGUES [15]. The obtained results presented good agreement as shown in Table 1.

\section{Analysed specimens}

The analysis was carried out considering as studying subject a thin-walled column constituted by concrete $\mathrm{C} 20$ reinforced by CA50 steel bars. The concrete Poisson's ratio and its deformation module value were fixed at 0.17 and $21300 \mathrm{MPa}$, respectively. The steel Young modulus and the steel yielding stress were fixed, respectively, at $210000 \mathrm{MPa}$ and $500 \mathrm{MPa}$.

For the reaction activation energy was adopted the value of $8500 \mathrm{~m}^{3}$.Pa. mol-1, proposed by GHANEM et al. [6]. And, for the Avogadro's number, it was used the conventional value 6.02214129 x 1023 mol-1.

\section{Figure 6 - Displacement on "x" direction at the instant of loading in case "1"}
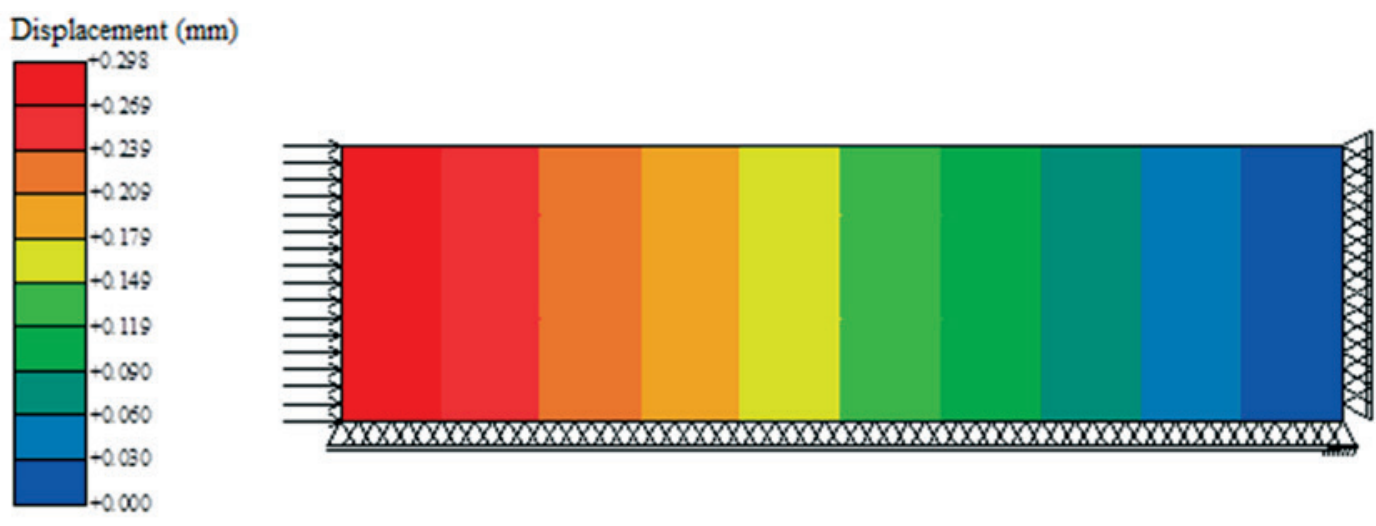


\section{Figure 7 - Stresses on "x" direction at the instant of loading in case "1"}
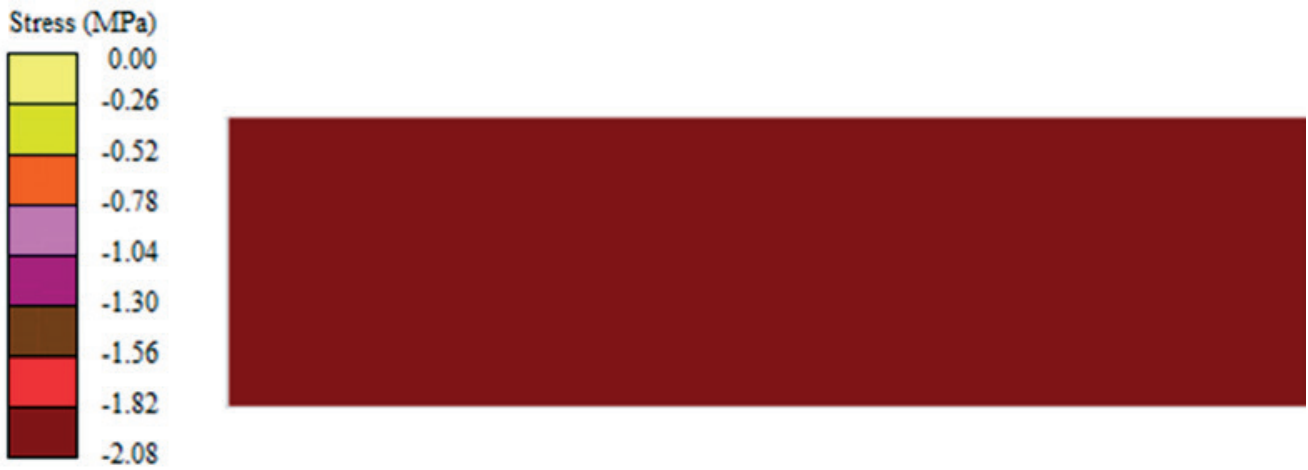

For the concrete modulus of deformation and the compressive strength degradation intensity factors, were adopted the values $A_{E}$ $=0.3$ and $A_{f}=0.4$, respectively, that was based on the experimen-

tal results obtained by SWAMY and AL-ASALI [17].

The studied columns are $3.00 \mathrm{~m}$ height and presents rectangular cross-section $1.60 \mathrm{~m}$ width and $0.20 \mathrm{~m}$ thick, and was submitted,

\section{Table 2 - Studied models and displacements}

\begin{tabular}{|c|c|c|c|c|c|}
\hline \multirow{2}{*}{ Case } & \multirow{2}{*}{$\mathrm{T}\left({ }^{\circ} \mathrm{C}\right)$} & \multirow{2}{*}{ As $\left(\mathrm{cm}^{2}\right)$} & \multirow{2}{*}{$\sigma(\mathrm{MPa})$} & \multicolumn{2}{|c|}{ Displacement } \\
\hline & & & & Loading & AAR \\
\hline 1 & 20 & 12.80 & 2.0 & 0,30 & $-0,27$ \\
\hline 2 & 20 & 12.80 & 4.0 & 0,61 & $-0,14$ \\
\hline 3 & 20 & 12.80 & 8.0 & 1,30 & 0,00 \\
\hline 4 & 20 & 20.00 & 2.0 & 0,30 & $-0,27$ \\
\hline 5 & 20 & 20.00 & 4.0 & 0,61 & $-0,13$ \\
\hline 6 & 20 & 20.00 & 8.0 & 1,30 & 0,00 \\
\hline 7 & 20 & 32.00 & 2.0 & 0,30 & $-0,26$ \\
\hline 8 & 20 & 32.00 & 4.0 & 0,61 & $-0,13$ \\
\hline 9 & 20 & 32.00 & 8.0 & 1,30 & 0,00 \\
\hline 10 & 50 & 12.80 & 2.0 & 0,30 & $-0,28$ \\
\hline 11 & 50 & 12.80 & 4.0 & 0,61 & $-0,14$ \\
\hline 12 & 50 & 12.80 & 8.0 & 1,30 & 0,00 \\
\hline 13 & 50 & 20.00 & 2.0 & 0,30 & $-0,27$ \\
\hline 14 & 50 & 20.00 & 4.0 & 0,61 & $-0,13$ \\
\hline 15 & 50 & 20.00 & 8.0 & 1,30 & 0,00 \\
\hline 16 & 50 & 32.00 & 2.0 & 0,30 & $-0,26$ \\
\hline 17 & 50 & 32.00 & 4.0 & 0,61 & $-0,13$ \\
\hline 18 & 50 & 32.00 & 8.0 & 1,30 & 0,00 \\
\hline 19 & 100 & 12.80 & 2.0 & 0,30 & $-0,27$ \\
\hline 20 & 100 & 12.80 & 4.0 & 0,61 & $-0,14$ \\
\hline 21 & 100 & 12.80 & 8.0 & 1,30 & 0,00 \\
\hline 22 & 100 & 20.00 & 2.0 & 0,30 & $-0,27$ \\
\hline 23 & 100 & 20.00 & 4.0 & 0,61 & $-0,13$ \\
\hline 24 & 100 & 20.00 & 8.0 & 1,30 & 0,00 \\
\hline 25 & 100 & 32.00 & 2.0 & 0,30 & $-0,26$ \\
\hline 26 & 100 & 32.00 & 4.0 & 0,61 & $-0,13$ \\
\hline 27 & 100 & 32.00 & 8.0 & 1,30 & 0,00 \\
\hline
\end{tabular}




\section{Figure 8 - Displacement on "x" direction due to AAR}

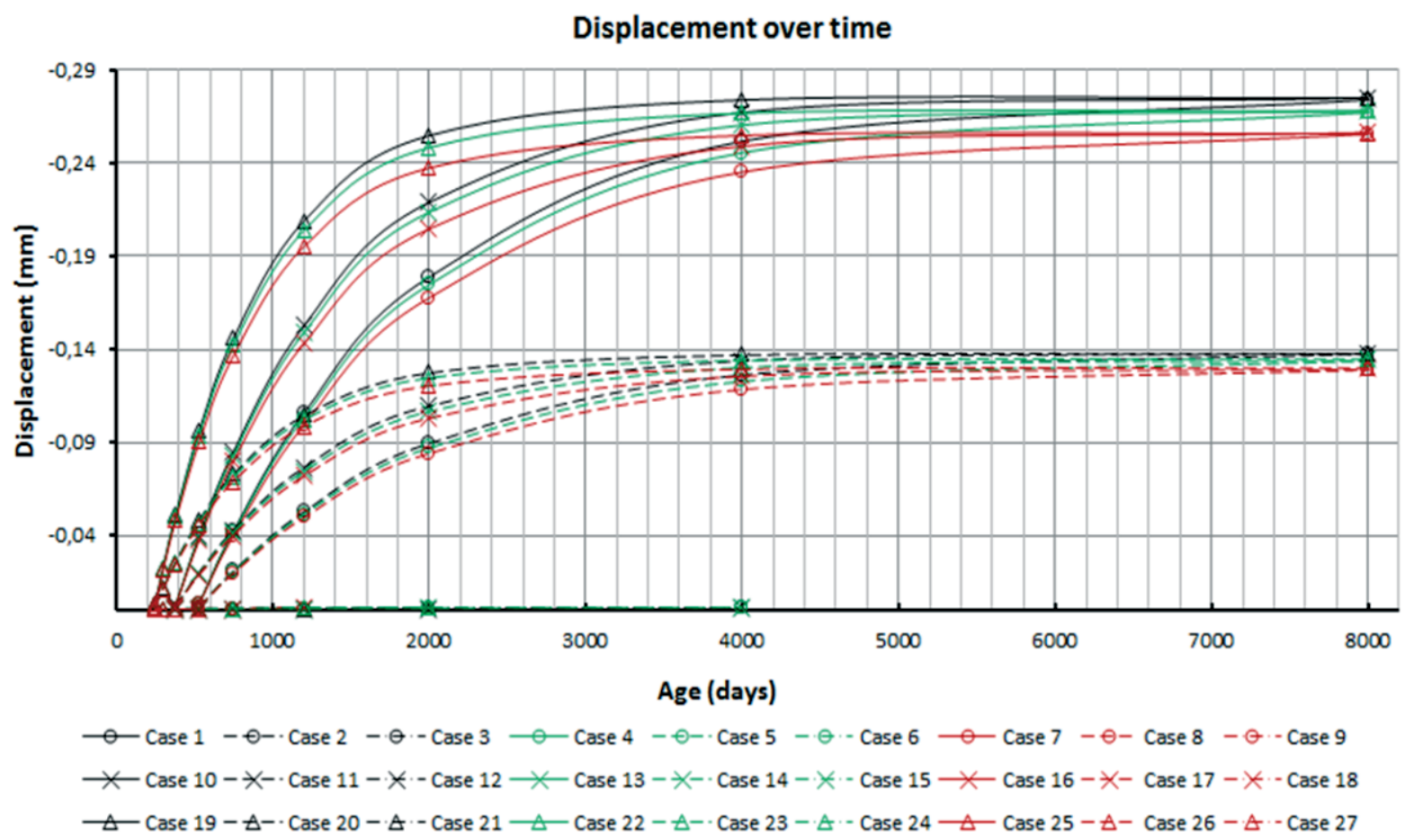

after 28 days, computed from the concrete casting date, to a uniformly distributed load along its top cross section area, Figure 5. For the purposes of the structural member graphic representation it was promoted a $90^{\circ}$ rotation on its longitudinal axis, which was drawn on this fashion in order to coincide with the horizontal direction in the page plane (direction " $x$ "). Taking advantage of the its symmetry, the problem mathmatical domain at the "xy" plane was defined as shown in Figure 5.

For the plane finite elements was adopted the square shape and for the problem domain discretization was considered that both types of finite element are $0.10 \mathrm{~m}$ length, resulting for the finite element mesh 240 plane elements and 120 bar elements, Figure 5.
The analysis was performed over twenty-seven cases, differentiated among themselves by the concrete solid mass temperature, by the steel bar reinforcement cross-sectional area and by the compressive stress magnitude, as shown in table 2.

\section{Results and discussions}

The obtained results showed that, for the "1", "4", "7", "10", "13", "16", "19", "22" and "25" cases, for which the compressive stress in the column longitudinal axis direction is the order of 2.0 MPa, the displacements and the stresses fields at the instant of loading presented themselves as shown in figures 6 and 7 , respectively. The

Figure 9 - Displacement on "x" direction due to AAR at 8000 days of age of concrete for the case "1"
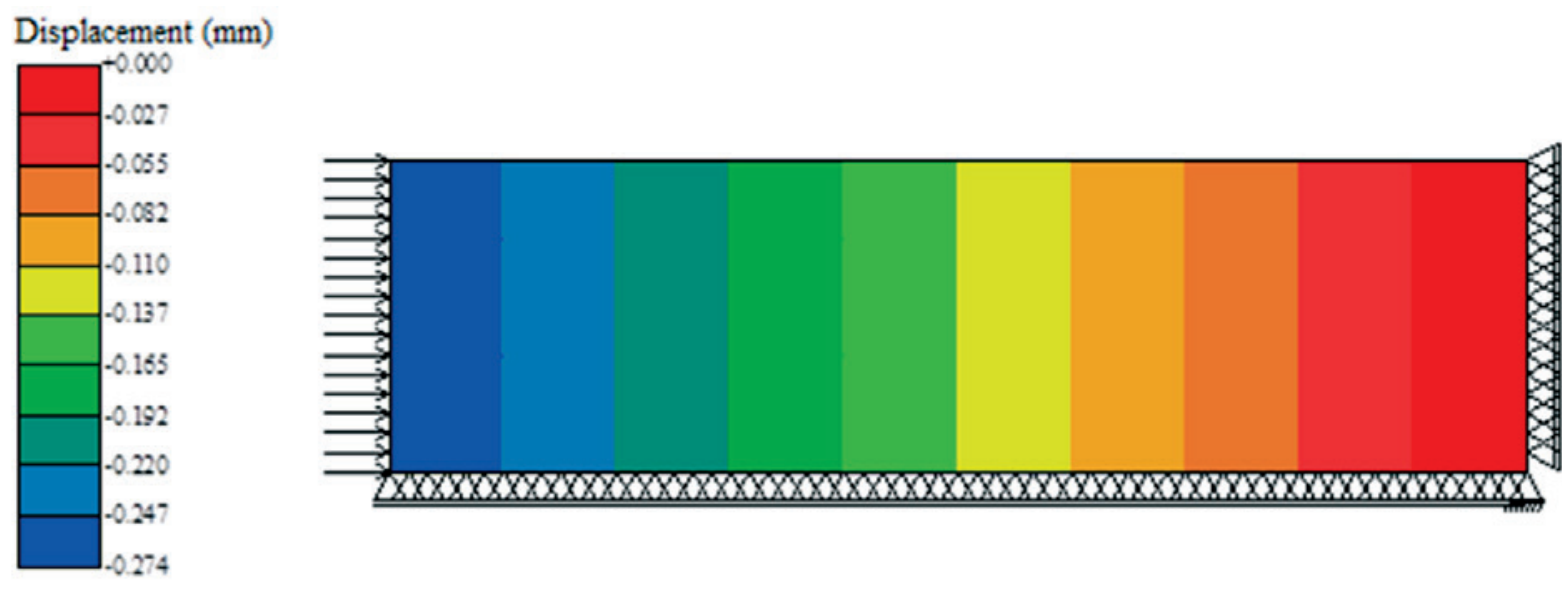


\section{Figure 10 - The concrete solid mass displacements initiation on the "x" direction due to AAR}

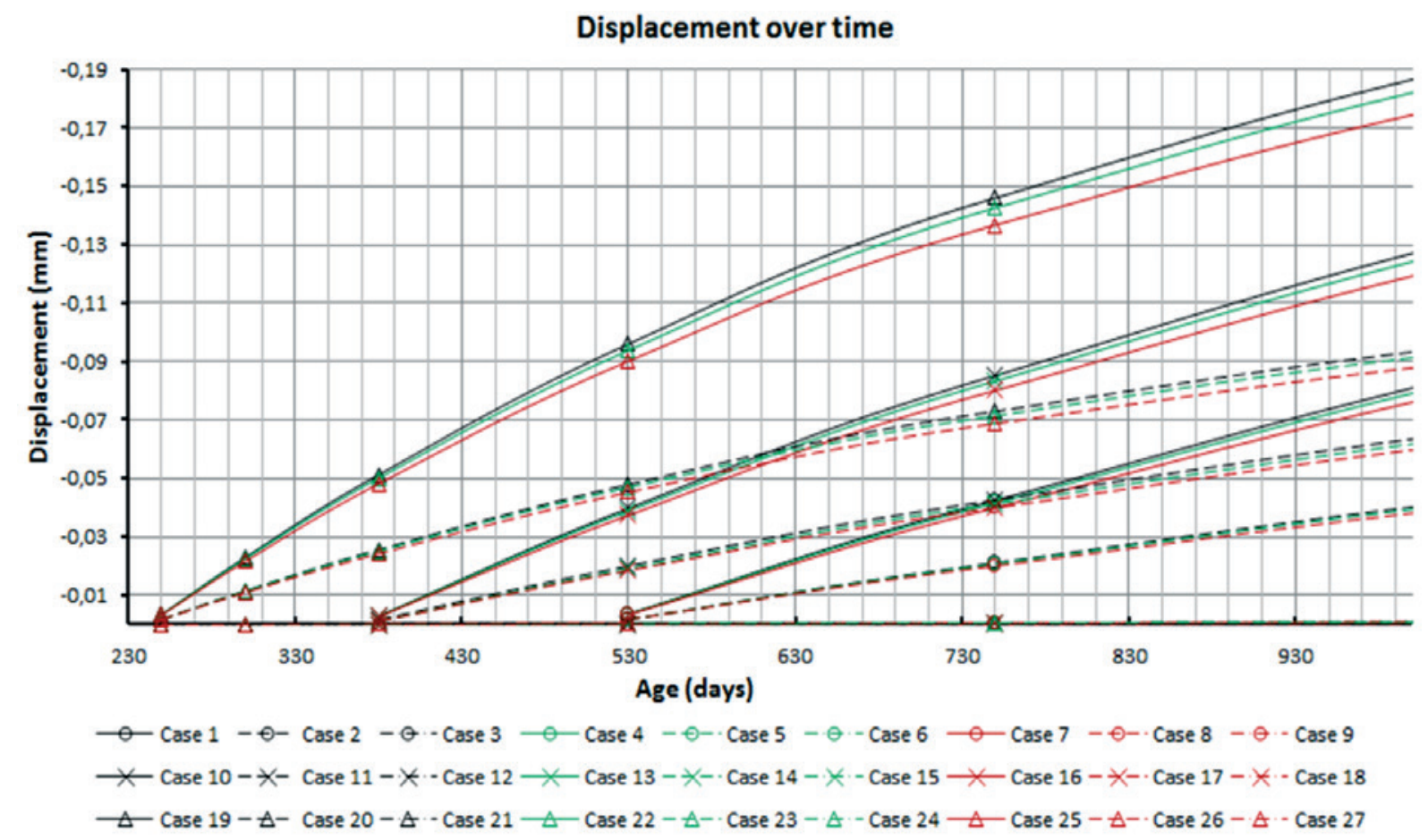

structural member shortening was by $0.3 \mathrm{~mm}$, approximately. For the cases concerning to the stress magnitude by 4.0 and $8.0 \mathrm{MPa}$, that shortening was by $0.6 \mathrm{~mm}$ and $1.3 \mathrm{~mm}$, respectively, table 2 . Once the AAR swelling effect on concrete solid mass was triggered, the columns stretched themselves progressively as shown on the curves of Figure 8. It may be identified in that picture three distinct bundles of lines, pointing out that, for compression stresses of lesser magnitude, the expansions by AAR assumed larger values. It also may be noted that, for the "1", "4", "7", "10", "13", "16", "19", "22" and " 25 " cases, the AAR swelling was already stabilized after 8000 days from its beginning, and the corresponding displacement field exhibited the aspect shown in Figure 9. The final stretches were closed to $0.27 \mathrm{~mm}$, representing $90 \%$ of the contraction value occurred at the instant of loading, table 2 . For the " 2 ", "5", "8", "11", "14", "17", "20", "23" and "26" cases, corresponding to the stress magnitude of $4.0 \mathrm{MPa}$, the column response was similar, nevertheless, the stretching was about $0.13 \mathrm{~mm}$, table 2 , reaching thus $21 \%$ of the contraction at the instant of loading. For the other cases, which are referred to the stress magnitude of $8.0 \mathrm{MPa}$, the expansions due to AAR swelling were, virtually, null, as expected from the problem modeling criterion.

It was also noted that, for the "1", "2", "4", "5", "7" and "8" cases, referring to the $20^{\circ} \mathrm{C}$ temperature, the expansions by AAR solely began and one stabilized at 510 and 8000 days, respectively, from the AAR beginning. For "10", "11", "13", "14", "16" and "17" cases, in turn, related to the $50^{\circ} \mathrm{C}$ temperature, such a dates were 370 and 6000 days, and, for "19", "20", "22", "23", "25" and "26" cases, con- cerning to the $100^{\circ} \mathrm{C}$ temperature, they were 240 and 4000 days, Figure 8 and Figure 10.

One may be observed that the columns referring to "2", " 5 ", " 8 ", "11", "14", "17", "20", "23" and " 26 " cases, whose stress magnitude is of $4.0 \mathrm{MPa}$, presented final displacements due to AAR, virtually, identical. Such a response, specially, for the " 2 ", "11", and " 20 " cases, differentiated among themselves, solely, by the temperature, were to be expected because that parameter doesn't affect the AAR final swelling magnitude. The temperature catalytic effect is restricted to the reaction kinetic exerting, exclusively, the accelerator effect on the concrete matrix expansions. On the other hand, for those columns of this set, whose reinforcement is different from case to case, such king of response stays on apparent contradiction in terms to the expected results because, for the greatest reinforcement ratio the corresponding displacement would be smaller, due to the steel bars restraint effect. Nevertheless, for these cases, it must consider that, as higher the reinforcement ratio as higher will be its capacity to absorb forces and, therefore, to make decrease the stress on the concrete solid mass, promoting, in this way, higher AAR deformations. Thus, the greatest deformations by AAR associated to the lowest compressive stress magnitude, may have compensated the steel reinforcement restraint effect that, certainly, would result on smaller stretching. Such explanation is valid, included, for those cases in which the stress magnitude was of $2.0 \mathrm{MPa}$.

It may also be note that, during the AAR swellings, the normal stresses in the concrete solid mass presented fairly discrete magni- 
Figure 11 - Stresses on the concrete solid mass on the " $x$ " direction during the AAR swelling Evolution of concrete stress at the coordinates: $x=1,489 \mathrm{~m}$ e $y=0,189 \mathrm{~m}$

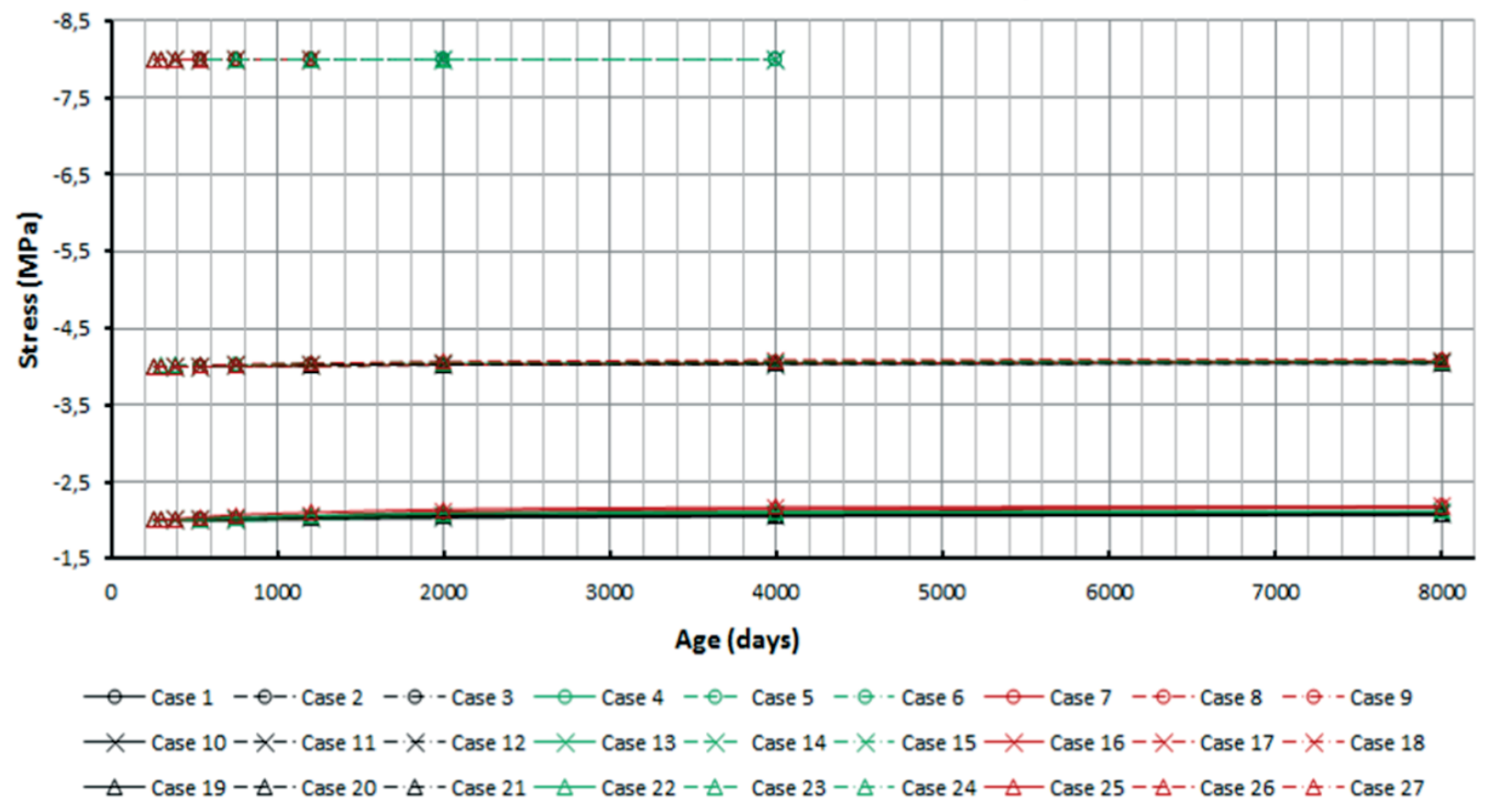

tude variations, Figure 11. One may attribute this kind of response to the fact that the deformations by AAR have been little significant. For the cases referring to the higher reinforcement ratio, as the case 7 , the stress fields at the instant of loading presented discrete disturbing in the immediate vicinity of the load application surface that was attenuated by the deformation reversal trend due to AAR expansions, as shown in figures 12 and 13.

For the aims of this work it was introduced a parameter named
Normalized Compressive Stress defined as the ratio between the normal stress magnitude and the stress value corresponding to the concrete failure.

The deleterious effect of the AAR was obvious because, despite its expansions had promoted little variations in the concrete solid mass stresses fields, it made decrease the concrete strength, inducing remarkable variations in the Normalized Compressive Stress, Figure 14. For the "1", “4”, "7", "10", “13", "16”, "19", "22"

\section{Figure 12 - Stresses on " $x$ " direction at the instant of loading for the case 7}

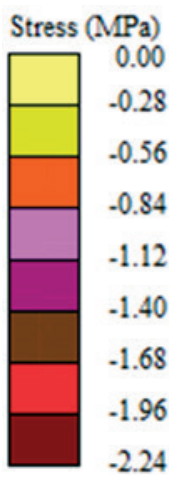


Figure 13 - Stresses on " $x$ " direction at 8000 days due to AAR for the case 7

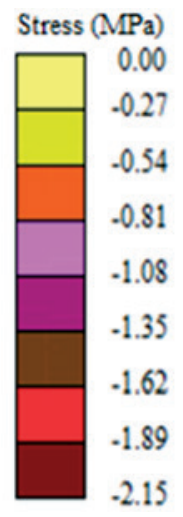

and "25" cases, the increase was discreet, remaining a substantial safety margin at 8000 days, computed from AAR initiation. On the other hand, for the " 2 ", " 5 ", "8", "11", "14", "17", "20", "23" and "26" cases, it was noted an increase from 0.20 to 0.67 , at that age, remaining a safety margin of $33 \%$. For the " 3 ", "12" and " 21 " cases, for which the compressive stress was about 8.0 MPa and for the smallest reinforcement steel ratio, the increase in Normal- ized Compressive Stress was from 0.40 to 1.0 , indicating a high probability of concrete failure condition by crushing, at 1600, 2500 and 3600 days, respectively, after the AAR swelling has triggered. It may note that, in the cases for which was prescribed the higher temperatures and, therefore, the AAR swelling triggered in younger ages of concrete, the structural member failure was anticipated. Such reality induces the need to set up different schedules for

Figure 14 - Normalized Compressive Stress time evolution by AAR

Normalized compressive stress over time

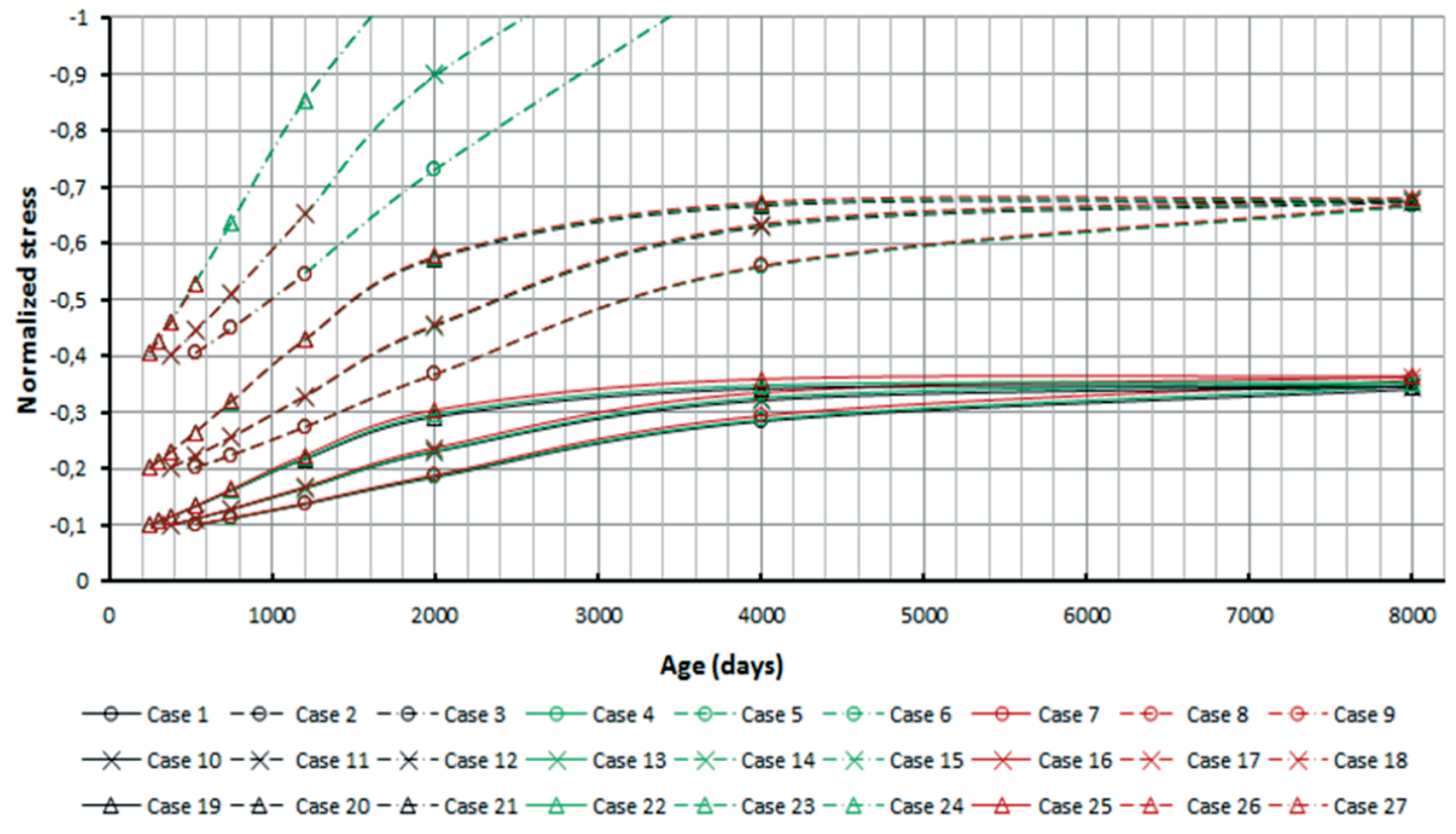




\section{Figure 15 -Stresses on " $y$ " direction " $y$ " at the instant of loading for case 3}
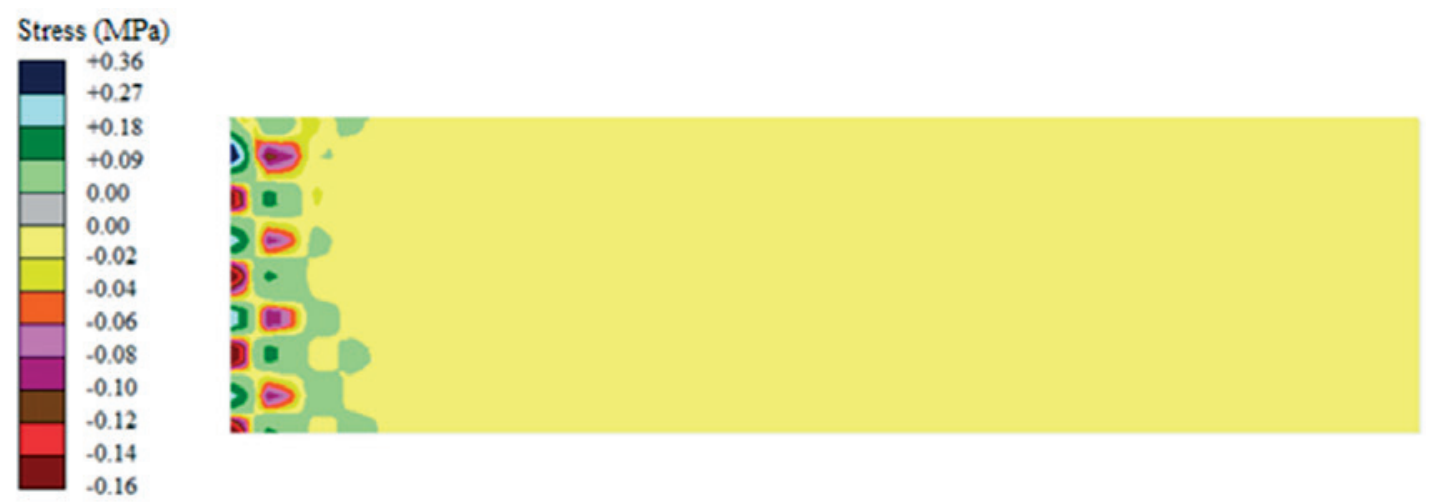

corrective interventions, aimed at preserving the satisfactory mechanical performance of the structural member, and even reduce the legal prediction of its lifetime.

In a general way the stresses on the concrete solid mass at the " $y$ " direction remained stable presenting magnitudes far below its tensile strength, as shown by the fields of figures 15 and 16. For the columns referring to " 8 ", " 17 " and " 26 " cases, especially, that presents the greatest steel bars reinforcement ratio, it occurred Tensile Normalized Stress increase, at a point localized into the loading introduction region at the cross-section gravity center vicinity. Such an increase hit, after 8000 days, referred to the AAR initiation age, a value about 0.83 . The " 6 ", " 15 " and " 24 " cases, and, the "9", "18" and " 27 " cases, corresponding to the stress magnitude equal to $8.0 \mathrm{MPa}$, presented Tensile Normalized Stress of 0.4 and 0.7 , respectively, at the concrete AAR swelling beginning. Such a parameter has assumed value equal to 1.0, establishing great probability condition of failure, after a period since 500 days until 3100 days, Figure 17. It is observed that, as higher the reinforcement ratio and the concrete solid mass temperature, the material failure was triggered more early, Figure 17. Nevertheless, the fact that, such stresses have been greatest for higher reinforcement ratios drops the association of such an occurrence to the cracking effort reported by MADUREIRA [10].

\section{Conclusions}

This work refers to AAR swelling effect analysis in reinforced concrete thin-walled columns, on the basis of a thermodynamic model, from a non-linear orthotropic framework and the finite element approximation.

The analysis subject of this work was carried out to evaluate the reinforcement ratio, the compressive stress and the temperature influences on the AAR swelling effects.

For the aims of this work it was introduced a parameter named Normalized Compressive Stress defined as the ratio between the normal stress magnitude and the stress value corresponding to the concrete failure.

The obtained results showed that, for the analyzed cases, the expansions had already been stabilized at 8000 days after the swelling by AAR initiation.

\section{Figure 16 - Stresses on "y" direction at 8000 days by AAR for case 3}
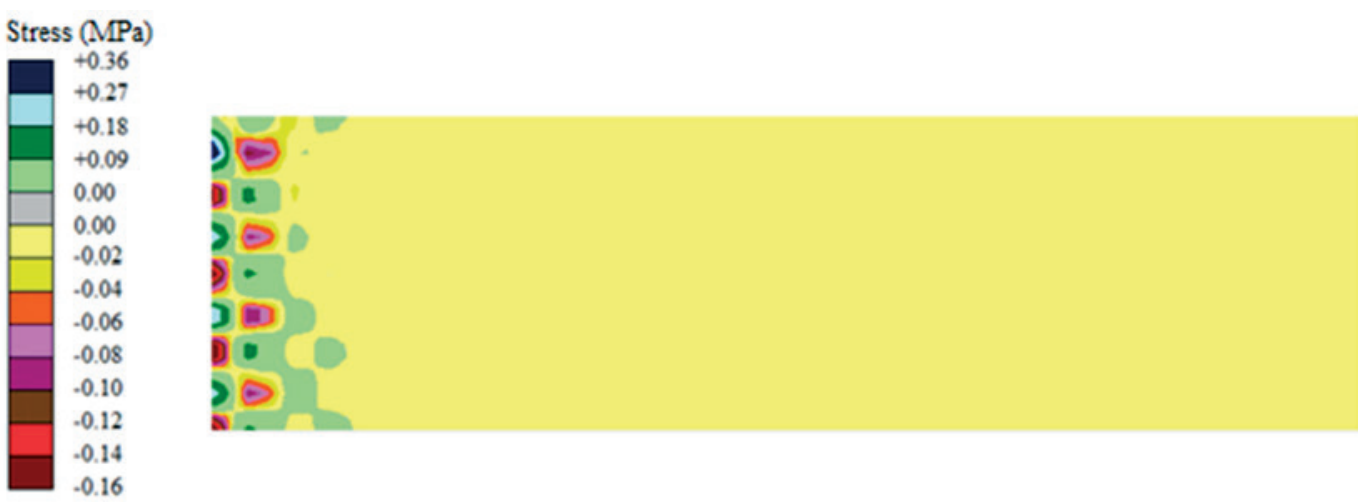


\section{Figure 17 - Normalized Tensile Stress variations due to AAR}

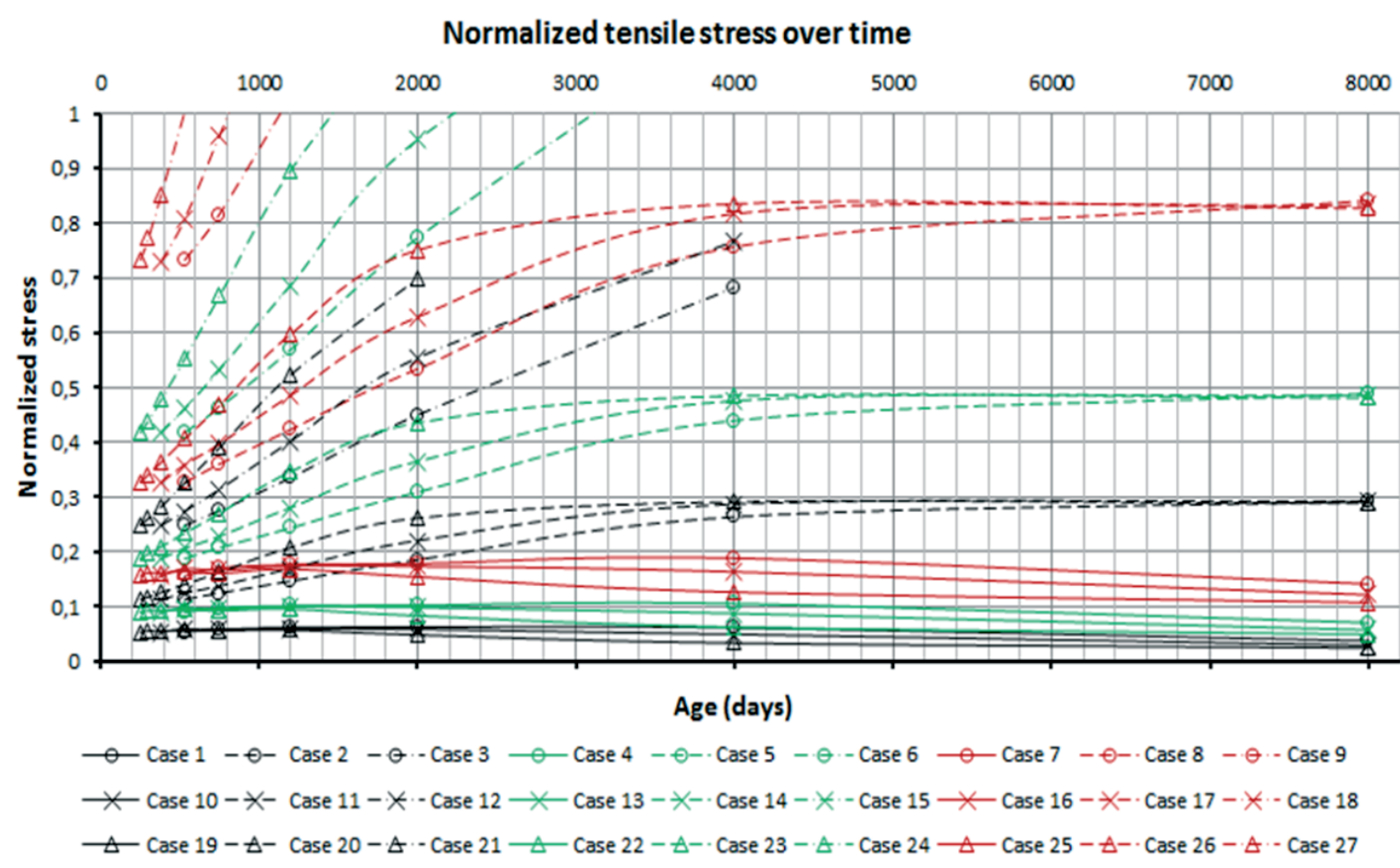

Such a results revealed that the column stretching induced by the AAR was as smaller as higher the compressive stress magnitude and that the swellings were virtually null for the stress magnitude about 8.0 MPa, confirming the stress confinement effect on the AAR expansions.

The AAR deleterious effect on the concrete solid mass was obvious that's why such chemical reaction promoted the structural member mechanical performance impoverishment, specially, the concrete strength reduction. Such an effect was remarkable because, for the cases corresponding to greatest compressive stress magnitude, although the variability of such kind of stress was negligible, the Normalized Compressive Stress hit values equal to the unit, featuring a condition of imminent failure.

For the cases referring to the higher reinforcement ratio, the stress fields at the instant of loading presented discrete disturbing in the immediate vicinity of the load application surface that was attenuated by the deformation reversal trend due the AAR expansions. The results corroborated that the temperature exerts, exclusively, the accelerator effect on the concrete matrix expansions, because, although, for higher temperatures, the swelling effect had been triggered and stabilized at earlier ages of concrete, it did not influence the final AAR displacement magnitude. Nevertheless, one must consider this effect relevant that's why, for the higher temperatures, the structural member failure was anticipated inducing the needing for set up different elapsing time for corrective interventions, aimed to preserving the satisfactory mechanical performance of the structural member, and even to reduce the legal prediction of its lifetime.
In addition, although a higher reinforcement ratio must exert a higher AAR deformation restraint effect, on the other hand, because the steel bars supplementary capacity to absorb forces, the compression stress magnitude on the concrete solid mass would be smaller, thus contributing to higher AAR deformation. One may considered that these effects were mutually compensated that's why the AAR deformation magnitude held, virtually, constant. Such a trend is a probable indication that the adoption of passive reinforcement on concrete confers low effectiveness to the AAR swelling effect attenuation.

For some of the cases referring to the greatest steel bars reinforcement ratio it was developed Tensile Normalized Stress increase at " $y$ " direction by AAR that culminated into a great probability condition of failure. Nevertheless, considering that such an effect have been more pronounced for higher reinforcement ratios, its association to the cracking effort reported by MADUREIRA [10] must be discarded. To diagnose the actual consequences of this fact, on the overall performance of the structural member, it would be necessary to analyze the cracking propagation over time in a detailed fashion.

\section{Acknowledgements}

This report is part of a research work on the numerical simulation of the reological effects on reinforced concrete members supported by the Fundação Coordenação de Aperfeiçoamento de Pessoal de Nível Superior - CAPES, by the Programa de Apoio a Planos de Reestruturação e Expansão das Universidades Federais - 
REUNI, and, by the Pró-Reitoria de Pesquisa da Universidade Federal do Rio Grande do Norte - UFRN. Their support is gratefully acknowledged.

\section{References}

[1] ASSOCIAÇÃO BRASILEIRA DE NORMAS TÉCNICAS. NBR 6118: Projeto de Estruturas de Concreto - Procedimento. Rio de Janeiro: ABNT, 2014.

[2] CAPRA, B. e BOURNAZEL, J. P. Modeling of Induced Mechanical effects of Alkali-Aggregate Reactions. Cement and Concrete Research, Vol. 28, N.2, pp. 251-260. 1998.

[3] CAPRA, B. e SELLIER, A. Ortotropic Modelling of Alkali-Aggregate Reaction in Concrete Structures: Numerical Simulations. Mechanics of Materials, Vol 35, pp. 817-830, 2002.

[4] CHARLWOOD, R.G. A Review of Alkali-aggregate Reaction in Hydro-electric Plants and Dams. Hydropower Dams, n 1, pp. 73-80. 1994.

[5] DESAI, C.S. e SIRIWARDANCE, H.J. Constitutive Laws for Engineering Material. Prentice-Hall, New Jersey, 1972.

[6] GHANEM, H., ZOLLINGER, D. e LYTTON, R Predicting ASR aggregate reactivity in terms of its activation energy. Construction and Building Materials, Vol. 24, pp. 1101-1108, 2010.

[7] HOGNESTAD, E. A Study of Combined Bending and Axial Load in Reinforced Concrete Members. Bolletin n. 399, Engineering Experiment Station, University of Illinois, Urbana, Illinóis, Vol. 49, n 22. 1951.

[8] KUPFER, H.B.; GERSTLE, K.H. Behaviour of Concrete under Biaxial Stresses. Journal of Engineering Mechanics, [S.I.], vol. 99, n. 4, p. 853-866, 1973.

[9] KWAK, H.G. and FILIPPOU, F.C. Finite Elements Analysis of Reinforced Concrete Structures under Monotonic Loads. Report UCB/SEMM-90/14, Berkeley, California. 1990. s

[10] MADUREIRA, E.L. Simulação Numérica do Comportamento Mecânico de Elementos de Concreto Armado Afetados pela Reação Álcali-Agregado. Tese de Doutorado, Universidade Federal de Pernambuco, Recife, p. 208. 2007.

[11] MADUREIRA, E.L. e SILVA, A.L.A. Project1 - Programa para visualização de campos de tensões resultates de analises não lineares de modelos bidimensionais de elementos finitos. Versão 1.0, Rio Grande do Norte: DEC/UFRN. 2013.

[12] PIETRUSZCZAC, S. On the Mechanical Behaviour of Concrete Subjected to Alkali-Aggregate reaction. Computers \& Structures. Vol. 58, n. 6, pp. 1093-1097. 1996.

[13] PITANGUEIRA, R. L. S. e PARENTE JR., E. NLPOS - Programa para visualização de resultados de analises não lineares de modelos bidimensionais de elementos finitos. Versão 1.0, Rio de Janeiro: DEC/PUC-Rio. 1997.

[14] POOLE, A.B. The Alkali-silica Reaction in Concrete. Ed Swamy, Blackie, London. 1992. s

[15] RODRIGUES, E.C. (2014). Análise Numérica do Efeito de Fatores Influentes da Reação Álcali-Agregado no Desempenho de Estruturas de Concreto. Dissertação de Mestrado. Universidade Federal do Rio Grande do Norte. Natal. p. 121. 2014.

[16] STANTON, T.E. Expansion of Concrete Through Reaction Between Cement and Aggregates. Proceedings of the American Society of Civil Engineering. 1940.
[17] SWAMY, R. N., e AL-ASALI, M. M. Engineering Properties of Concrete Affected by Alkali-Silica Reaction. ACI Materials Journal, September/October 1988, pp.367-374. 1988. 